\title{
Criterion-Based Metrics for Range Restriction Corrections
}

\author{
Dustin A. Fife ${ }^{1}$, Thomas W. O'Kane ${ }^{1}$, \& Valerie Davis-Lamastro ${ }^{1}$ \\ 1 Rowan University
}

\begin{abstract}
For decades, it has been suggested organizations utilize mechanical decisions. Unfortunately, organizations continue to rely on holistic judgments. Perhaps part of the reasons organizations continue to rely on judgment when making decisions is because the reported statistics associated with mechanical judgments (e.g., $R^{2}$ ) are not intuitive to stakeholders. For example, it is unclear in terms of turnover whether an $R^{2}$ change from 0.23 under the old (holistic) system to an $R^{2}$ of 0.27 under the (mechanical) system is enough of an improvement to justify the cost of changing selection methods. In this paper, we argue that researchers instead report changes in criteria of interest (e.g., absenteeism rate before versus after utilizing a mechanical selection system). This can be accomplished by utilizing a multiple imputation algorithm that simulates optimal selection decisions. Additionally, we provide both an R-package, as well as a point-and-click Shiny app that allows researchers to easily estimate intuitive statistics (e.g., improvement in turnover, proportion of applicants for which an optimal and holistic system agree).
\end{abstract}

Suppose an organization has, over the last several years, experienced a steady decline in sales from those they hire. More specifically, the average net sales (i.e., average number of sales - amount spent per employee) per quarter is only $\$ 2,000$. With the growing costs of overhead, the company recognizes their current situation is unsustainable.

Consequently they decide to hire an outside consultant. The consultant learns this organization has historically selected employees using holistic or "clinical" judgments (Meehl, 1954) that aggregate diverse predictors (e.g., cognitive ability, biodata, interview performance) into a judgment of "suitability" (Hunter \& Schmidt, 2004). This consultant is familiar with the superiority of mechanical judgments over holistic judgments (Kuncel, Klieger, Connelly, \& Ones, 2013) and recommends the company modify their selection process.

We wish to thank the editor and reviewers for their helpful feedback during the submission of this manuscript.

Correspondence concerning this article should be addressed to Dustin A. Fife, 201 Mullica Hill Road Glassboro, NJ 08028. E-mail: fife.dustin@gmail.com 
Subsequently, the consultant obtains the company's selection records, then builds a mechanically-weighted regression model that predicts net sales from the predictors used for selection, yielding an $\mathrm{R}^{2}$ of 0.21 , which is then corrected for range restriction, yielding a new estimate of $R^{2}=0.29$.

At this point, the organization is left to wonder: Is 0.29 a large value? What is $R^{2}$ under the current system? Will the organization recoup the cost of the consultant by how much they will improve their workforce? How much more will they expect to make per employee under the new system?

Stakeholders in organizations are no strangers to numbers. The health of an organization is often measured in dollars, turnover, absences, growth, and stocks. Yet the numbers routinely used for decision-making in selection research (e.g., correlation coefficients, Cohen's $d$ values) are much more abstract, and conceptually quite distant from metrics organizations find interesting. However, even those who routinely work with statistics will struggle to answer many (or any) of these questions.

This is, perhaps, one of the major oversights of the selection literature. As far as we know, there are no methods available to convert standardized statistical metrics into numbers understandable to organizations. This paper attempts to address this oversight. We propose a novel method for evaluating the efficacy of proposed selection systems, one that expresses selection decisions in terms of the criteria organizations value. With this new method, researchers and organizations alike will be able to answer many important questions, such as

- If I change from a suboptimal to an optimal system, how much should I expect the turnover rate to decrease?

- What is the minimum improvement in average job performance I can expect under an optimal system?

- What percentage of employees I rejected should have been hired?

Before introducing this new method, we begin by briefly reviewing the selection literature, then place it within the context of missing data theory. We then explain how to estimate what we call criterion-based metrics. Next, we demonstrate this method on three simulated examples, then conclude with an illustration with actual data.

\section{Corrections for Range Restriction}

Since Pearson (1903), we have known the effects of range restriction on correlation coefficients. When selection is made top-down, range restriction tends to attenuate correlation coefficients, yielding biased estimates of their population values. Fortunately, corrections are readily available for most common situations organizations will encounter, including direct range restriction (i.e., Case II), indirect range restriction (i.e., Case III), and their extensions (e.g., Fife, Hunter, \& Mendoza, 2016; Bobko, Roth, \& Bobko, 2001; Le, Oh, Schmidt, \& Wooldridge, 2016; Roth, 1994; Schmidt, Oh, Le, In-Sue, \& Le, 2006).

Most of these corrections require population estimates of the variables used for selection. Generally, this is not a problematic assumption, since organizations are legally required to 
retain selection information (U.S Equal Employment Opportunity Commission, 2020). (It can be problematic, however, when performing meta-analyses where applicant data may be unavailable. In this paper, we assume the organization still has these records.)

The vast majority of range restriction corrections attempt to correct the correlation coefficient, with a few exceptions, such as Cohen's $d$ (Bobko et al., 2001; Li, 2015), reliability coefficients (Fife, Mendoza, \& Terry, 2012; Sackett, Laczo, \& Arvey, 2002), and variance/covariance matrices (Aitken, 1935; Lawley, 1944). These corrections are employed using formulae that yield a disattenuated estimate of the statistic of interest.

Unfortunately, these standard approaches suffer from several weaknesses. First, standard errors are often difficult to obtain (Mendoza, 1993). Second, all these methods make the standard assumptions of linear models, including homoscedasticity, linearity, and normality (Ghiselli, Campbell, \& Zedeck, 1981; Lord \& Novick, 1968; Thorndike, 1949). This will be problematic when one is attempting to correct for selection effects in a non-normally distributed criterion, such as turnover or absenteeism. Third, while these corrections may be able to recover statistical estimates, these corrections say nothing about the scores themselves, which are of critical importance to organizations. Put differently, these methods do not actually estimate the missing values, but instead estimate statistics associated with these values.

Fortunately, missing data theory allows us to address all these limitations.

\section{Missing Data}

Under a missing data paradigm, selection causes criterion scores to be "missing." Rubin (1976) developed the theory of missing data that is now mainstream among missing data researchers, and is making its way into selection research (Fife et al., 2017a; Gross \& McGanney, 1987; Mendoza, 1993). Briefly, Rubin defines three different missing data mechanisms: Missing Completely at Random (MCAR), Missing at Random (MAR), and Missing Not at Random (MNAR).

MCAR means the probability a score is missing depends entirely on chance. For example, an employee may have rejected a job offer because they suffered an injury that made them unable to work. Since suffering an injury is a relatively random event, we can classify this as MCAR. Under a MCAR situation, one can easily recover the metrics of interest (e.g., turnover rates) from the available data alone.

MAR means the probability a score is missing depends only on variables that are observed and measured. For example, suppose an organization selects employees based solely on their IQ scores, then measures job performance (JP) some time later for those selected into the organization. In this case, and assuming no attrition, the probability of an indivdiual missing their JP scores is dependent entirely on their IQ scores. Because IQ scores were measured, our missing JP scores are MAR. When data are MAR, some missing data strategies will yield unbiased estimates, but not all. Listwise deletion (i.e., simply removing those rows with missing data) will yield biased results. Multiple imputation and 
maximum likelihood methods, on the other hand, will be unbiased. We will speak more of these methods later.

Finally, MNAR means the probability a score is missing depends on variables that are not available. For example, if employees drop out of the organization because of a lack of motivation, and if motivation was not measured before they left, the data are MNAR. Unfortunately, obtaining unbiased estimates from MNAR data is really tricky, and require fairly restrictive assumptions (Enders, 2010; Heckman, 1979).

Within the missing data paradigm, there are two broad approaches to handling missing data. The first is maximum likelihood methods, including the Expectation Maximization algorithm (Dempster, Laird, \& Rubin, 1977; Schafer, 1997) and Full Information Maximum Likelihood (FIML) within structural equation modeling software. Much like the standard corrections for range restriction, these methods recover statistical estimates without actually estimating the missing values. The second approach is Multiple Imputation (MI). Unlike all the other methods, MI does impute the missing data, which will allow us to estimate criterion-based metrics (see Pfaffel, Kollmayer, Schober, \& Spiel, 2016 for an example). In other words, MI overcomes all three limitations of traditional corrections. With MI, it naturally estimates standard errors, it allows users to fit generalized linear models to estimate non-normally distributed variables, and it generates estimated criterion scores for those not selected.

\section{Obtaining Criterion-Based Metrics Using MI}

Recall that our goal is to provide intuitive metrics that estimate how much a new selection system will improve upon the current system. To get to that point, we need three critical pieces of information: (1) We need to know the baseline metrics of interest for the current sample. For example, we will need current turnover rates, current average absenteeism, average net sales, etc. These metrics should be readily available from the sample of incumbents. (2) We need to know the optimal weights that maximize the relationship between the predictor(s) and the criterion. If we have access to the predictor variables for incumbents, the data are MAR and it is therefore possible to obtain unbiased estimates of the optimal weights. (3) We need estimated criterion scores (e.g., who quit the organization, number of abscences, sales numbers) for those who were not hired. Having these scores will allow us to compute the metrics of interest (e.g., turnover rates) for those people the selection system should have selected, but did not (as well as for those the system did not select and should not have selected).

The latter two pieces of information (optimal weights and predicted scores) require some sophistication. In the next section, we will explain how these can be obtained.

\section{Calculating Optimal Weights from Incumbent Samples}

It has long been established that the slope between predictor and criterion is unaffected by selection (Lord \& Novick, 1968). This situation is called "direct range restriction" (Sackett \& Yang, 2000; Thorndike, 1949). (The correlation coefficient, on the other hand, is affected 
by selection). Likewise, under indirect range restriction, the conditional slope between the incidentally-restricted variable and the outcome is also unaffected by selection (Lord \& Novick, 1968). What this means for our purposes is that we can estimate the optimal predictor(s)-to-criterion weights using only the selected sample (see Fife et al., 2017b).

The only caveat is that we must utilize an appropriate statistical model. While we might be able to use standard multiple regression to model job performance scores, standard regression models will not work when estimating turnover or absenteeism, simply because the predictor(s)/criterion relationships will be nonlinear and non-normally distributed. However, this is a minor complication; most standard statistical software will be able to model a logistic regression (e.g., for turnover), poisson regression (e.g., for abstenteeism), gamma regression (e.g., for sales), etc.

The weights obtained from this regression model can then be used as a measure of organizational "suitability" for each person. Our definition of suitability deviates from the traditional conceptualization (Hunter \& Schmidt, 2004). Traditionally, suitability is a holistic judgment call made by the organization, one that aggregates diverse sources of information. It is more of a construct than a measure. Also, the traditional suitability definition is quite vague with respect to the criterion; it is not a measure that maximizes a particular outcome per se. Our definition, on the other hand, is an operational definition. It is mechanical and is mathematically linked to a specific outcome (e.g., turnover or absenteeism).

However, it is important to keep the predicted scores on a continuous scale. Many software programs may default to outputing predicted responses. For example, if one is modeling a logistic regression, the software may report ones and zeros. These are less informative than their continuous counterparts (e.g., the predicted scores on the log odds scale, or even the predicted probabilities).

\section{Calculating Predicted Scores for Those Not Hired}

While it is trivially easy to estimate the optimal weights from incumbent samples, it is not so trivial to obtain predicted scores for those not hired, or least it is difficult to do so with appropriate standard errors. Of course, one could use the model from the previous step to then estimate the predicted scores for those not selected (top of Figure 1), but this would introduce bias in the standard errors. Alternatively, one could predict the missing scores, but add noise to the predicted values (as in the bottom of Figure 1). The amount of noise added is sampled from a normal distribution with a standard deviation equal to the model's residual error, since residual standard errors are also unaffected by selection (Lord \& Novick, 1968). This approach is called stochastic regression. The problem with this approach is that it treats the estimated scores as if they're observed scores. This too will yield biased estimates of standard errors.

A better approach is to perform stochastic regression, but multiple times. For example, we might impute the missing values 10 times. Now, each person has 10 estimates of their scores, rather than one. Doing so explicitly accounts for the uncertainty inherent in 

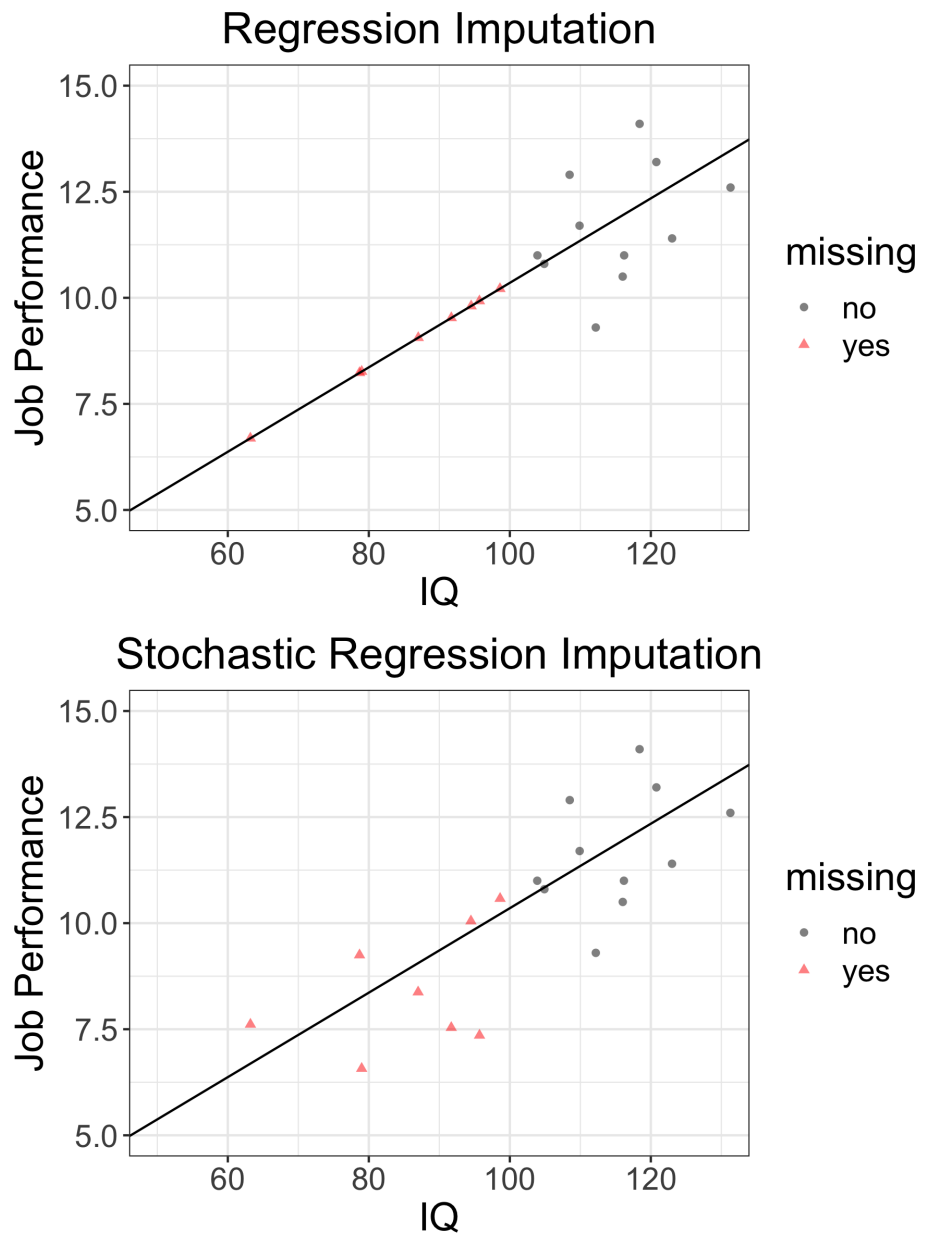

Figure 1. Demonstration of two methods of imputation. The top image is called regression imputation where each person's missing score is replaced by the best-fitting regression estimate. This approach will yield unbiased estimates of the regression line, but will artificially attenuate standard errors. The bottom image shows stochastic regression imputation, which adds noise to the prediction. This too artificially attenuates standard errors because it treats the imputed scores as if they're actual scores. A better approach is multiple imputation, which essentially performs stochastic regression multiple times. 
estimating missing scores. This approach is called Multiple Imputation (MI) (Rubin, 1987). ${ }^{1}$ MI yields unbiased estimates of the metrics of interest with appropriate standard errors.

For our purposes, we wish to estimate the value of the criterion (e.g., absenteeism, turnover, net sales) for those not hired. Once we have the estimated criterion scores, as well as the optimal weights, we can then compute turnover rates under a (simulated) system that selects people who were not originally selected. We can also obtain appropriate standard errors from which to make inferences and develop confidence intervals.

\section{Approach: Summary}

Our approach to making selection decisions recognizes that standard metrics (e.g., Cohen's $d$, correlation coefficients) are not intuitive to organizations, or even to researchers. Instead, we advocate that researchers report predicted improvements over existing selection systems using criterion-based metrics, such as turnover and absenteeism. To do so, the following steps are required:

1. Calculate the criterion-based metric for the current sample (e.g, turnover rate, average JP score).

2. Build a multiple regression model (e.g., poisson for abstenteeism, logistic for turnover, standard regression for job performance) that predicts the criterion from the predictor(s). These predicted scores serve as our operational definition of "suitability."

3. Simulate selection by first rank-ordering the suitability scores, then marking the top scores as "selected." The number marked should be equal to the number of incumbents.

4. Use MI to repeatedly estimate the criterion scores for those not selected, and use those scores to compute the criterion-based statistic. For example, for each imputation, we might estimate turnover under the new system by computing the proportion of (simulated) selected applicants the model predicts will quit.

5. Average the criterion-based estimates from the imputations in Step \#4 (and aggregate estimates of variability using the appropriate pooling equations; Little \& Rubin, 2014) and compare the mean estimate to the value obtained from Step \#5.

To clarify how to do this, we will demonstrate with three examples. The first example will utilize a very small dataset to illustrate the calculations. The next two will use larger datasets. In all cases, we will highlight how this method provides intuitive estimates across diverse types of criterion variables where traditional methods would fail.

\footnotetext{
${ }^{1}$ This is a slight simplication of the MI algorithm. In reality, the regression line and residual standard error are estimated after each new imputation using Markov Chain Monte Carlo methods, and new noise is added based on the newly estimated regression line/standard error. For more information, see Enders (2010).
} 


\section{Demonstrations}

\section{Example 1 - Turnover with a poor selection system}

Suppose an organization wishes to reduce turnover. Currently, they have a $50 \%$ average turnover rate within the first year of employment. To select employees, they use the variables IQ, biodata, conscientiousness, and interview performance. Suppose, unbeknownst to the researcher, the optimal way to weight these variables is

- $\mathrm{IQ}=2.4$

- Biodata $=1.2$

- Conscientiousness $=0.6$

- Interview $=0$

For simplicity, we assume these weights are applied to standardized versions of each variable. Doing so ensures the weights are proportional. For example, 2.4 (the weight for IQ) is twice as large as 1.2 (the weight for biodata), indicating that IQ is twice as important a predictor as biodata. Likewise, biodata is twice as important as conscientiousness.

Of course, the organization has no idea what the optimal weights are. Rather, the organization has historically relied on "gut feelings," which leads to a suboptimal weighting of selection information, where the weights are actually weighted in inverse order of importance:

- $\mathrm{IQ}=0$

- Biodata $=0.6$

- Conscientiousness $=1.2$

- Interview $=2.4$

To address their poor turnover statistics, they wish to build a composite score for future applicants. Fortunately, this organization has retained selection information from the last several years. For example, the data may look like Table 1. Note that the predictors have been converted to $Z$ scores to make the weighted calculations easier. These data can be used to build a mechanical composite for future selection cohorts. To do so, we will follow the five steps listed previously.

Step 1: Compute Turnover From Incumbents. This first step is trivially easy; we simply need to divide the number who quit (5) by the number selected (10), which results in a turnover rate of 0.50 . This value will serve as the baseline upon which we compare the proposed selection system.

Step 2: Estimate Suitability. With the dataset from the current cohort (Table 1), the organization can develop a logistic regression model that predicts who will turn over based on the selection variables,

$$
\log \left(\frac{p(\text { quit })}{p(\text { not quit })}\right)=b_{0}+b_{1} \mathrm{IQ}+b_{2} \text { Biodata }+b_{3} \text { Conscientiousness }+b_{4} \text { Interview }
$$


Table 1

Example Dataset of Simulated Predictor Variables and an Outcome.

\begin{tabular}{llllll}
\hline IQ & Biodata & Conscientiousness & Interview & Selected & Quit \\
\hline-0.147 & 0.813 & 0.939 & -0.726 & No & \\
0.081 & -0.060 & 0.548 & 0.005 & Yes & No \\
-1.798 & -1.215 & 0.003 & -1.312 & No & \\
1.825 & -0.951 & -0.282 & -0.765 & No & \\
1.057 & -0.882 & 0.079 & -0.569 & No & \\
-1.830 & -0.979 & -0.186 & -2.093 & No & \\
-0.734 & -0.082 & -0.656 & 0.545 & Yes & Yes \\
0.414 & 1.119 & 1.001 & 0.671 & Yes & No \\
0.976 & 0.995 & 0.181 & -1.013 & No & \\
-0.207 & 1.496 & -1.006 & 0.950 & Yes & Yes \\
-0.532 & -1.321 & -0.915 & -0.033 & No & \\
0.134 & -1.589 & 0.857 & 0.002 & Yes & Yes \\
-0.513 & 0.225 & -1.030 & 0.480 & Yes & No \\
1.008 & -0.736 & -0.708 & 0.706 & Yes & No \\
0.212 & 0.065 & 0.463 & 1.099 & Yes & Yes \\
-0.178 & -1.119 & -2.602 & -0.430 & No & \\
-1.492 & -0.340 & 0.238 & 0.542 & Yes & Yes \\
1.866 & 0.804 & 1.655 & 0.844 & Yes & No \\
-0.346 & -0.472 & -0.501 & -0.591 & No & \\
0.513 & 0.282 & 0.439 & -0.162 & No & \\
\hline & & & & & \\
\hline
\end{tabular}

Based on missing data theory, the coefficients from this model (i.e., $b_{0}, b_{1}, b_{2}, b_{3}$, and $\left.b_{4}\right)$ are unbiased estimates of their population values $\left(\beta_{0}, \beta_{1}\right.$, etc.). These estimated weights can then be used to modify their current system. In other words, the values of $b_{0}, b_{1}, b_{2}, b_{3}$, and $b_{4}$ can be used to develop "suitability" scores.

For example, suppose we built a model using the full version of the data from Table 1. If so, our standardized estimates would be:

- $\mathrm{IQ}=-3.93$

- Biodata $=-1.72$

- Conscientiousness $=-0.22$

- Interview $=2.05$

(Note: these estimates are negative because the suitability scores predicted who would quit, and higher IQ scores mean lower probabilities of quitting). These weights can then replace those in the equation above to develop a suitability score:

$\widehat{\text { suitability }}=-3.93 \times \mathrm{IQ}+-1.72 \times$ Biodata $+-0.22 \times$ Conscientiousness $+2.05 \times$ Interview $(2)$

We could then plug in these coefficients in our existing dataset to retroactively estimate 
Table 2

The Same Example Dataset as The Previous Table, But This Table is Sorted by Suitability and the Top Performers are Marked as Selected.

\begin{tabular}{llllllll}
\hline IQ & Biodata & Conscientiousness & Interview & Suitability & Selected & Selected2 & Quit \\
\hline 0.976 & 0.995 & 0.181 & -1.013 & -8.132 & No & Yes & \\
1.866 & 0.804 & 1.655 & 0.844 & -7.815 & Yes & Yes & No \\
1.825 & -0.951 & -0.282 & -0.765 & -7.503 & No & Yes & \\
1.057 & -0.882 & 0.079 & -0.569 & -4.280 & No & Yes & \\
0.513 & 0.282 & 0.439 & -0.162 & -3.392 & No & Yes & \\
-0.147 & 0.813 & 0.939 & -0.726 & -2.982 & No & Yes & \\
0.414 & 1.119 & 1.001 & 0.671 & -2.860 & Yes & Yes & No \\
1.008 & -0.736 & -0.708 & 0.706 & -1.549 & Yes & Yes & No \\
0.081 & -0.060 & 0.548 & 0.005 & -0.788 & Yes & Yes & No \\
-0.207 & 1.496 & -1.006 & 0.950 & -0.056 & Yes & Yes & Yes \\
-0.346 & -0.472 & -0.501 & -0.591 & 0.608 & No & No & \\
0.212 & 0.065 & 0.463 & 1.099 & 0.746 & Yes & No & Yes \\
0.134 & -1.589 & 0.857 & 0.002 & 1.566 & Yes & No & Yes \\
-0.178 & -1.119 & -2.602 & -0.430 & 1.858 & No & No & \\
-0.513 & 0.225 & -1.030 & 0.480 & 2.379 & Yes & No & No \\
-0.734 & -0.082 & -0.656 & 0.545 & 3.829 & Yes & No & Yes \\
-0.532 & -1.321 & -0.915 & -0.033 & 4.041 & No & No & \\
-1.830 & -0.979 & -0.186 & -2.093 & 4.164 & No & No & \\
-1.798 & -1.215 & 0.003 & -1.312 & 6.009 & No & No & Yes \\
-1.492 & -0.340 & 0.238 & 0.542 & 7.049 & Yes & No & \\
\hline
\end{tabular}

someone's suitability score, as in the column labeled "Suitability" in Table 2.

Step 3: Simulate Selection Based on Suitability Scores. Table 2 shows the same scores as Table 1, but these are sorted by suitability scores. Notice that, in addition to a "Suitability" column, another column has been added ("Selected (Optimal)"). This column simply categorizes the first 10 individuals as selected, which is the same number of individuals who were actually selected (though, of course, the actual individuals selected are different).

Although we have successfully simulated selection decisions, we still need to stochastically estimate who would quit in order to estimate the improvement of the new selection weights. We do this in the next section.

Step 4: Use MI to Estimate Who Would Have Quit. At this point, we can utilize MI to estimate the predicted response for each applicant, as well as standard errors. For this example, we only performed one imputation, which is shown in Table 3. The quit scores that were estimated are surrounded by parentheses. 


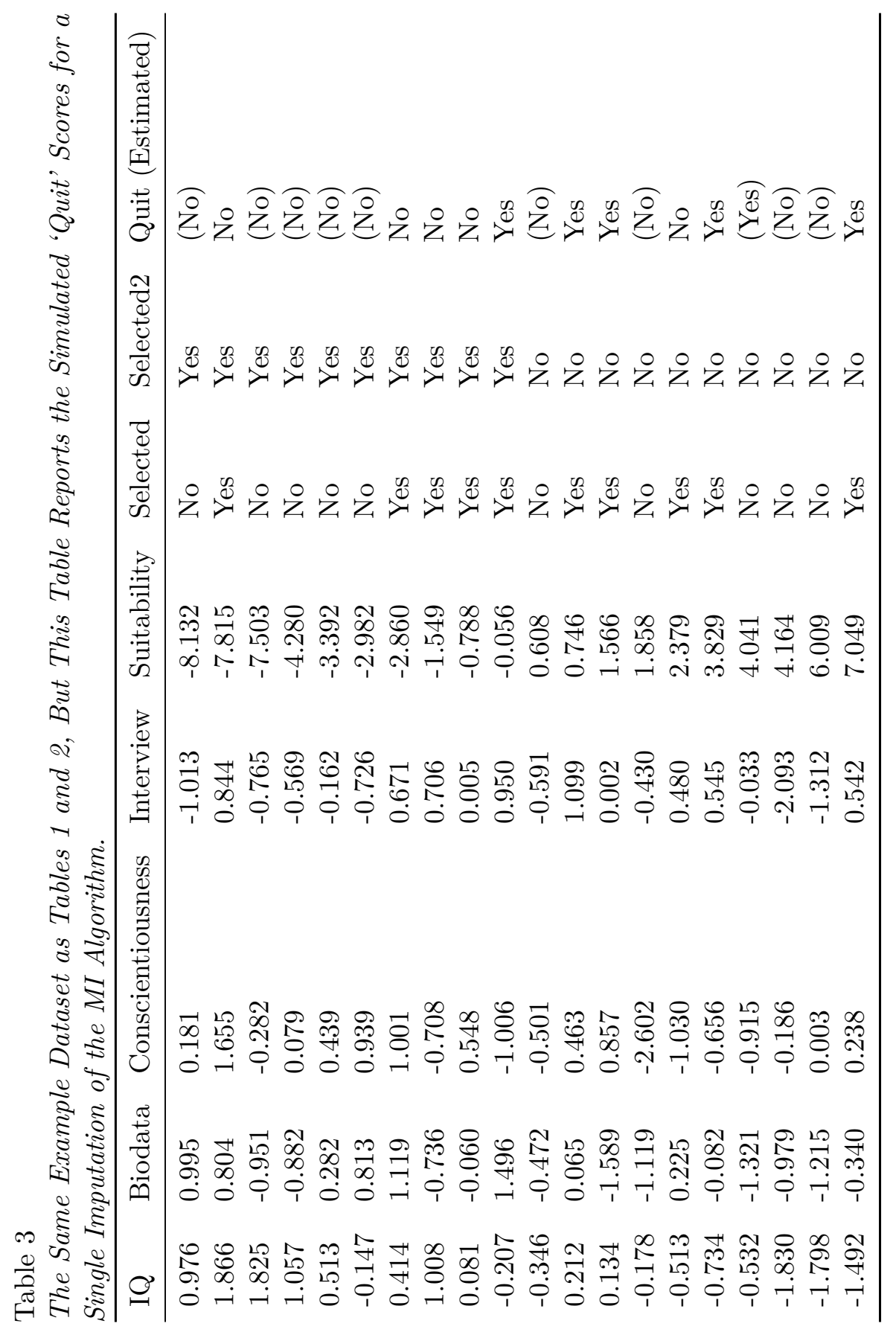


Step 5: Compute the Turnover Rate for the Simulated Data and Compare to the Actual Data. As with Step 1, computing the turnover rate is trivial, though this time we identify the proportion of simulated selected individuals who are categorized as quit. In this example, that is 0.10 , which is an improvement over the original value of 0.50 . Of course, if we were to really estimate these metrics, we should repeat the imputation multiple times. However, the purpose of this example is simply to illustrate the algorithm.

All the steps we have performed so far can be done with a few simple clicks, as demonstrated in the Appendix. This step-by-step example was merely to demonstrate the logic of the method.

In the following sections, we will forego showing the raw data as we have done in this section. Also, we will utilize much larger sample sizes, and with different scenarios.

\section{Example 2 - Absenteeism with a mediocre selection system}

The previous example showed how different the turnover rates might be from optimal turnover rates under a poorly designed system. Suppose, however, an organization is interested in reducing absenteeism. Further suppose the organization's selection system was good, but not optimal. More concretely, let us suppose the optimal weights are the same as they were before:

- $\mathrm{IQ}=2.4$

- Biodata $=1.7$

- Conscientiousness $=0.6$

- Interview $=0$

Now, however, the organization's weights are only slightly less different than optimal. In this example, the weights for IQ/biodata and conscientiousness/interview are flipped:

- $\mathrm{IQ}=1.7$

- Biodata $=2.4$

- Conscientiousness $=0$

- Interview $=0.6$

Using these weights, we simulated a scenario where abstenteeism is the criterion of interest. Briefly, we simulated 500 scores from a multivariate normal distribution to simulate the predictor scores. Next, the exponentiated optimal weights were used to simulate absences, and the suboptimal weights were used to quantify suboptimal suitability and make selection decisions.

We can now follow the same procedure as with the previous example: estimate suitability scores, categorize suitability scores to simulate selection under an optimal system, use MI to predict criterion scores, and compute the metrics of interest for each imputation. Now, however, the criterion (absenteeism) does not follow a Binomial distribution as before. Rather, it follows a Poisson distribution. As such, we need to modify the suitability estimates as well as the imputation model to account for that. The new suitability estimate will be: 
Table 4

Values of the Estimated Predictor Weights Under the Old System (In Odds Ratios), Under the New System, and the Actual Population Values.

\begin{tabular}{llll}
\hline & Odds Ratios (Current System) & Estimated Weights & Population Weights \\
\hline IQ & -3.02 & 2.54 & 2.40 \\
Biodata & -4.91 & 1.22 & 1.20 \\
Conscientiousness & -0.14 & 0.60 & 0.60 \\
Interview & -0.94 & 0.03 & 0.00 \\
\hline
\end{tabular}

$\log ($ absenteeism $)=b_{0}+b_{1} \mathrm{IQ}+b_{2}$ Biodata $+b_{3}$ Conscientiousness $+b_{4}$ Interview $=$ suitability

As before, our operational definition of suitability is tied directly to an outcome of interest (in this case, absenteeism). In this situation, however, the suitability score is on a $\log$ scale. Once again, the scale of the suitability score doesn't matter, provided both are on interval-level scales.

If we were to follow the same sequence of steps we did with the turnover example, but with the correct distribution (Poisson) and a much larger sample size (i.e., 500), the results show quite an improvement. The average number of absences under the existing system was 2.83 , while the estimated number of absences under the new system is 0.47 , which is a 6 -fold reduction.

It might also be interesting to estimate the weights of the current system, particularly when the existing system utilizes holistic judgments. This sort of analysis might inform organizations how they implicitly evaluated merit. To do so, one simply needs to fit a logistic regression model that predicts which applicants are selected using the predictors. The first column in Table 4 shows the odds ratios of this model. Not surprisingly, the model is able to pick up the rank order of the predictors. (As before, the numbers are negative because this model predicts who quits and higher scores on the predictors tend to make people less likely to quit). The second column shows the weights estimated from the poisson model that utilizes only the available data. These estimates are remarkably similar to the population values (third column).

\section{Example 3 - Job Performance With a Good Selection System and Adding Pre- dictors}

For our final example, we will simulate a situation where the researcher already has a good selection system in place, though they may not realize it. Perhaps, by chance, their holistic judgment was effective at selecting good employees, or perhaps they already have a mechanical process in place. However, they still see employees with lower job performance scores than they would like. As a result, they decide to add additional predictors to their selection system. For illustrative purposes, let us assume their old system used biodata and 
interview, appropriately weighted. Now they want to measure two new candidate predictors (IQ and conscientiousness) on the current cohort of applicants. These variables will be used to predict net sales, which we define as the difference between how much money the employee made in sales minus the money the company spent (e.g., in salary, commissions, benefits) to employ the incumbent. Let us assume the optimal weights are the same as before.

Fortunately, with the addition of the new predictors, the data are still MAR, and MI can still be used. For this illustration, we again simulated 500 applicants, but this time we treated the conscientiousness/biodata scores for those not selected as missing. As before, we then estimated suitability scores from a multiple regression model, although this model assumes normally distributed residuals. ${ }^{2}$

Under the old system, which correctly weighted the variables of interest, the average net sales was $\$ 2,816.83$ per quarter. With the addition of the two other variables, the average net sales increased to $\$ 5,476.03$, with a $95 \%$ confidence interval between $\$ 5,155.80$ and $\$ 5,796.26$.

\section{Applied Example}

Demonstrating this process with an applied example, we will use a real dataset consisting of 1,000 observations of assistant managers and managers from a large retail chain. The dataset includes ten variables that fall into one of three different categories. Measures of job performance (criterion variables) included task performance (skills in budgeting, sales projections, inventory control, etc.) and contextual performance (skills interacting with co-workers based on a 360 feedback process). Potential selection variables in the dataset were: score on an in-house cognitive ability test, overall rating from an assessment center, scores on dependability, achievement, and emotional stability scales, as well as an overall rating from the interview. Demographic variables included race and gender. While the dataset only included data for incumbent employees, it did allow us to imitate applicant selection on actual data. Furthermore, the data had to be arbitrarily transformed into another metric for privacy reasons.

For this example, we assumed applicants were selected based on the (standardized) weights shown in Table 5. (The "Random" column indicates that we added unreliability to the selection system). Using these weights, we created a linear combination which resulted in a "Suitability" variable. Applicants were then sorted on suitability, then the top $50 \%$ of performers were "selected." For those not selected, we marked their criterion scores as missing. Next, we used the maximizeDV function in the selection package within $\mathrm{R}$ to estimate the standardized weights under the current system, the mean score for task/contextual performance under the current system, the mean score for task/contextual performance under an optimal system, and the proportion of applicants for which the two selection systems (current/optimal) agree. We also plotted the estimated mean of the criterion scores for each imputation.

\footnotetext{
${ }^{2}$ It is unlikely sales are normally distributed, or even net-sales. Rather, a strictly positive distribution such as a gamma or exponential may be more appropriate. However, these examples are merely for illustrative purposes.
} 
Table 5

Weights Applied to the Dataset to Simulate Selection.

\begin{tabular}{|c|c|c|}
\hline Variable & & Weights \\
\hline Cognitive Abilit & & 0.20 \\
\hline Assessment Cen & r Score & 0.40 \\
\hline Dependability & & 0.10 \\
\hline Achievement & & 0.20 \\
\hline Emotional Stabi & & 0.05 \\
\hline Interview & & 0.40 \\
\hline Random & & 0.20 \\
\hline \multirow{2}{*}{\multicolumn{3}{|c|}{$\begin{array}{l}\text { Table } 6 \\
\text { Current Versus Optimal } \\
\text { Means/Percent Agreement for } \\
\text { the Actual Dataset Under Two } \\
\text { Criterion }\end{array}$}} \\
\hline & & \\
\hline & Task & Context \\
\hline Current Mean & 0.007 & 0.018 \\
\hline Optimal Mean & 0.088 & 0.089 \\
\hline$\%$ Agreement & 0.854 & 0.776 \\
\hline
\end{tabular}

\section{Applied Example: Results}

Figure 2 shows two violin plots with the raw data displayed as dots. In both plots, the solid horizontal line is the estimated mean for the current sample (task mean for the left plot, context mean for the right plot). Each dot represents the estimated mean for a particular imputation.

Table 6 shows the statistics for the applied example. In both cases, the majority of the imputations show at least a marginal improvement in the mean of the criterion under a modified selection system. The estimated mean for task went from 0.01 under the old system to 0.09 under the optimal system. The estimated mean for context went from 0.02 to 0.09. Note that these are in $z$-score units (since the scale of the original variable was arbitrary). Also, the percent agreement between old versus new for the task variable is 0.85 and for the context variable is 0.78 . Taken together, these results seem to indicate that the (simulated) selection system was not optimal, though the improvement from an optimal system isn't terribly impressive.

\section{Discussion}

In this paper, we have argued that standard metrics for range restriction corrections are not intuitive. For example, it is unclear what specific correlation values mean in terms of 

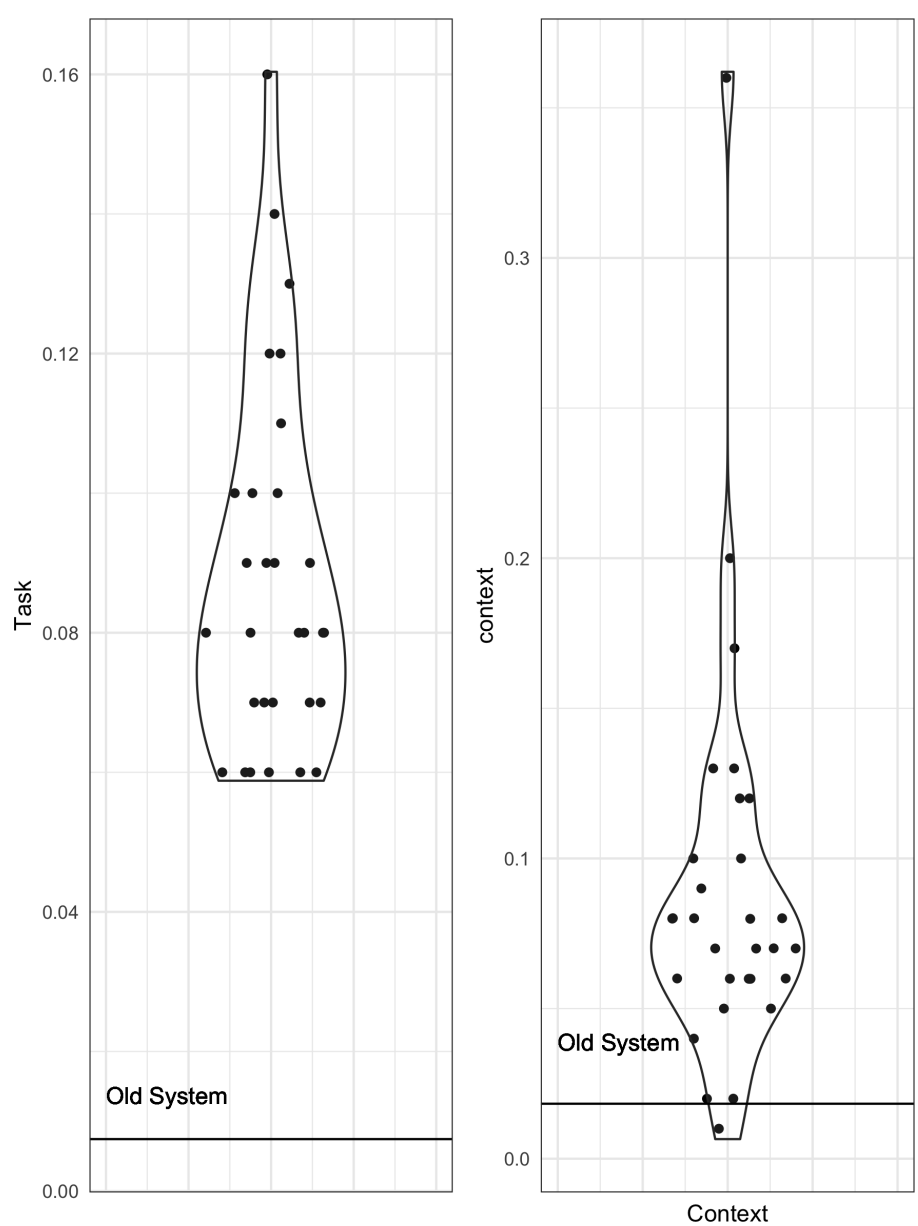

Figure 2. Violin plots of the mulitple imputation algorithm. Each dot represents the mean on task (left) and context (right) for each imputation. The horizontal line is the mean under the existing system.

metrics of interest to organizations, such as turnover rates, expenditures, and absenteeism. As an alternative, we propose a procedure that reports statistics in their original metrics (e.g. turnover, absenteeism, job performance, sales) which we believe are more intuitive to researchers and practitioners alike.

We also noted that organizations rely heavily on holistic decisions, despite their inferior predictive ability and weaker validity (Kuncel et al., 2013). Mechanical decisions, as well as range restriction corrections (SIOP, 2003) ought to be part of any validation procedure. Perhaps part of the reason mechanical decisions have not been adopted is because the statistics commonly reported for mechanical decisions (e.g., $R^{2}$ ) are not intuitive. This paper sought to make sound validation procedures much more palatable to researchers and practitioners. Utilizing MI, we can both estimate an optimal system and report its efficacy using more intuitive metrics.

The corrections shown in this paper are easy to use, and available in multiple formats: the selection package in $R$, as well as a point-and-click interface in a shiny web app. 
Further, these estimates can replace most estimates (e.g. direct/indirect corrected correlation coefficients) routinely reported in the selection literature. Because of this, we hope to see an increase in the use of both mechanical decision making as well as range-restriction-corrected correlations in future research.

\section{References}

Aitken, A. C. (1935). Note on Selection from a Multivariate Normal Population. Proceedings of the Edinburgh Mathematical Society, 4(2), 106-110. doi:10.1017/S0013091500008063

Bobko, P., Roth, P. L., \& Bobko, C. (2001). Correcting the Effect Size of d for Range Restriction and Unreliability. Organizational Research Methods, 4(1), 46-61. Retrieved from https://journals.sagepub.com/doi/pdf/10.1177/109442810141003

Dempster, A. P., Laird, N. M., \& Rubin, D. B. (1977). Maximum likelihood from incomplete data via the EM algorithm. Journal of the Royal Statistical Society: Series B (Methodological), 39(1), 1-22.

Enders, C. K. (2010). Applied missing data analysis. New York, NY: Guilford Press.

Fife, D. A., Hunter, M. D., \& Mendoza, J. L. (2016). Estimating Unattenuated Correlations With Limited Information About Selection Variables: Alternatives to Case IV. Organizational Research Methods, 19(4). doi:10.1177/1094428115625323

Fife, D. A., Mendoza, J. L., \& Berry, C. M. (2017a). Estimating Incremental Validity Under Missing Data. Multivariate Behavioral Research, 52(2). doi:10.1080/00273171.2016.1259099

Fife, D. A., Mendoza, J. L., \& Berry, C. M. (2017b). Estimating Incremental Validity Under Missing Data. Multivariate Behavioral Research, 52(2), 164-177.

Fife, D. A., Mendoza, J. L., \& Terry, R. (2012). The Assessment of Reliability Under Range Restriction. Educational and Psychological Measurement, 72(5), 862-888. doi:10.1177/0013164411430225

Ghiselli, E. E., Campbell, J. P., \& Zedeck, S. (1981). Measurement Theory for the Behavioral Sciences.

Gross, A. L., \& McGanney, M. L. (1987). The restriction of range problem and nonignorable selection processes. Journal of Applied Psychology, 72(4), 604-610.

Heckman, J. J. (1979). Sample Selection Bias as a Specification Error. Econometrica, 47(1), 153-161. doi:10.2307/1912352

Hunter, J. E., \& Schmidt, F. L. (2004). Methods of meta-analysis: correcting error and bias in research findings. Thousand Oaks, CA: Sage.

Kuncel, N. R., Klieger, D. M., Connelly, B. S., \& Ones, D. S. (2013). Mechanical versus clinical data combination in selection and admissions decisions: A meta-analysis. Journal of Applied Psychology, 98(6), 1060-1072. doi:10.1037/a0034156 
Lawley, D. N. (1944). A Note on Karl Pearson's Selection Formulae. Proceedings of the Royal Society of Edinburgh. Section A. Mathematical and Physical Sciences, 62(01), 28-30. doi:https://doi.org/10.1017/S0080454100006385

Le, H., Oh, I., Schmidt, F. L., \& Wooldridge, C. D. (2016). Correction for range restriction in meta-analysis revisited: Improvements and implications for organizational research. Personnel Psychology, 69(4), 975-1008.

Li, J. C.-H. (2015). Cohen's d Corrected for Case IV Range Restriction: A More Accurate Procedure for Evaluating Subgroup Differences in Organizational Research. Personnel Psychology, 68(4), 899-927. doi:10.1111/peps.12096

Little, R. J. A., \& Rubin, D. B. (2014). Statistical analysis with missing data. Hoboken, NJ: John Wiley \& Sons.

Lord, F. I., \& Novick, M. R. (1968). Statistical theories of mental test scores. Cambridge, MA: Addison-Wesley.

Meehl, P. (1954). Clinical versus statistical prediction: A theoretical analysis and a review of theevidence. Minneapolis, MN: University of Minnesota.

Mendoza, J. L. (1993). Fisher Transformations for Correlations Corrected for Selection and Missing Data. Psychometrika, 58(4), 601-615.

Pearson, K. (1903). Mathematical Contributions to the Theory of Evolution. XI. On the Influence of Natural Selection on the Variability and Correlation of Organs. Philosophical Transactions of the Royal Society of London. Series A, Containing Papers of a Mathematical or Physical Character, 200, 1-66.

Pfaffel, A., Kollmayer, M., Schober, B., \& Spiel, C. (2016). A missing data approach to Correct for direct and indirect range restrictions with a dichotomous criterion: A simulation study. PLoS ONE, 11(3), e0152330. doi:10.1371/journal.pone.0152330

Roth, P. L. (1994). Missing data: a conceptual review for applied psychologists. Personnel Psychology, 47(3), 537-560. doi:10.1111/j.1744-6570.1994.tb01736.x

Rubin, D. B. (1976). Inference and missing data. Biometrika, 63(3), 581-592. doi:10.1093/biomet/63.3.581

Rubin, D. B. (1987). Multiple imputation for nonresponse in surveys. New York, NY: Wiley.

Sackett, P. R., Laczo, R. M., \& Arvey, R. D. (2002). The effects of range restriction on estimates of criterion interrater reliability: Implications for validation research. Personnel Psychology, 55(4), 807-825.

Sackett, P. R., \& Yang, H. (2000). Correction for range restriction: An expanded typology. Journal of Applied Psychology, 85(1), 112-118.

Schafer, J. L. (1997). Analysis of incomplete multivariate data. Chapman; Hall/CRC.

Schmidt, F. L., Oh, I.-S., Le, H., In-Sue, O., \& Le, H. (2006). Increasing the accuracy of corrections for range restriction: implications for selection procedure validities and other 
research results. Personnel Psychology, 59(2), 281-305.

Thorndike, R. L. (1949). Personnel selection; test and measurement techniques. Oxford England: Wiley.

U.S Equal Employment Opportunity Commission. (2020). U.S Equal Employment Opportunity Commission. Retrieved from https://www.eeoc.gov/employers/recordkeeping.cfm

Aitken, A. C. (1935). Note on Selection from a Multivariate Normal Population. Proceedings of the Edinburgh Mathematical Society, 4(2), 106-110. doi:10.1017/S0013091500008063

Bobko, P., Roth, P. L., \& Bobko, C. (2001). Correcting the Effect Size of d for Range Restriction and Unreliability. Organizational Research Methods, 4(1), 46-61. Retrieved from https://journals.sagepub.com/doi/pdf/10.1177/109442810141003

Dempster, A. P., Laird, N. M., \& Rubin, D. B. (1977). Maximum likelihood from incomplete data via the EM algorithm. Journal of the Royal Statistical Society: Series B (Methodological), 39(1), 1-22.

Enders, C. K. (2010). Applied missing data analysis. New York, NY: Guilford Press.

Fife, D. A., Hunter, M. D., \& Mendoza, J. L. (2016). Estimating Unattenuated Correlations With Limited Information About Selection Variables: Alternatives to Case IV. Organizational Research Methods, 19(4). doi:10.1177/1094428115625323

Fife, D. A., Mendoza, J. L., \& Berry, C. M. (2017a). Estimating Incremental Validity Under Missing Data. Multivariate Behavioral Research, 52(2). doi:10.1080/00273171.2016.1259099

Fife, D. A., Mendoza, J. L., \& Berry, C. M. (2017b). Estimating Incremental Validity Under Missing Data. Multivariate Behavioral Research, 52(2), 164-177.

Fife, D. A., Mendoza, J. L., \& Terry, R. (2012). The Assessment of Reliability Under Range Restriction. Educational and Psychological Measurement, 72(5), 862-888. doi:10.1177/0013164411430225

Ghiselli, E. E., Campbell, J. P., \& Zedeck, S. (1981). Measurement Theory for the Behavioral Sciences.

Gross, A. L., \& McGanney, M. L. (1987). The restriction of range problem and nonignorable selection processes. Journal of Applied Psychology, 72(4), 604-610.

Heckman, J. J. (1979). Sample Selection Bias as a Specification Error. Econometrica, 47(1), 153-161. doi:10.2307/1912352

Hunter, J. E., \& Schmidt, F. L. (2004). Methods of meta-analysis: correcting error and bias in research findings. Thousand Oaks, CA: Sage.

Kuncel, N. R., Klieger, D. M., Connelly, B. S., \& Ones, D. S. (2013). Mechanical versus clinical data combination in selection and admissions decisions: A meta-analysis. Journal of Applied Psychology, 98(6), 1060-1072. doi:10.1037/a0034156 
Lawley, D. N. (1944). A Note on Karl Pearson's Selection Formulae. Proceedings of the Royal Society of Edinburgh. Section A. Mathematical and Physical Sciences, 62(01), 28-30. doi:https://doi.org/10.1017/S0080454100006385

Le, H., Oh, I., Schmidt, F. L., \& Wooldridge, C. D. (2016). Correction for range restriction in meta-analysis revisited: Improvements and implications for organizational research. Personnel Psychology, 69(4), 975-1008.

Li, J. C.-H. (2015). Cohen's d Corrected for Case IV Range Restriction: A More Accurate Procedure for Evaluating Subgroup Differences in Organizational Research. Personnel Psychology, 68(4), 899-927. doi:10.1111/peps.12096

Little, R. J. A., \& Rubin, D. B. (2014). Statistical analysis with missing data. Hoboken, NJ: John Wiley \& Sons.

Lord, F. I., \& Novick, M. R. (1968). Statistical theories of mental test scores. Cambridge, MA: Addison-Wesley.

Meehl, P. (1954). Clinical versus statistical prediction: A theoretical analysis and a review of theevidence. Minneapolis, MN: University of Minnesota.

Mendoza, J. L. (1993). Fisher Transformations for Correlations Corrected for Selection and Missing Data. Psychometrika, 58(4), 601-615.

Pearson, K. (1903). Mathematical Contributions to the Theory of Evolution. XI. On the Influence of Natural Selection on the Variability and Correlation of Organs. Philosophical Transactions of the Royal Society of London. Series A, Containing Papers of a Mathematical or Physical Character, 200, 1-66.

Pfaffel, A., Kollmayer, M., Schober, B., \& Spiel, C. (2016). A missing data approach to Correct for direct and indirect range restrictions with a dichotomous criterion: A simulation study. PLoS ONE, 11(3), e0152330. doi:10.1371/journal.pone.0152330

Roth, P. L. (1994). Missing data: a conceptual review for applied psychologists. Personnel Psychology, 47(3), 537-560. doi:10.1111/j.1744-6570.1994.tb01736.x

Rubin, D. B. (1976). Inference and missing data. Biometrika, 63(3), 581-592. doi:10.1093/biomet/63.3.581

Rubin, D. B. (1987). Multiple imputation for nonresponse in surveys. New York, NY: Wiley.

Sackett, P. R., Laczo, R. M., \& Arvey, R. D. (2002). The effects of range restriction on estimates of criterion interrater reliability: Implications for validation research. Personnel Psychology, 55(4), 807-825.

Sackett, P. R., \& Yang, H. (2000). Correction for range restriction: An expanded typology. Journal of Applied Psychology, 85(1), 112-118.

Schafer, J. L. (1997). Analysis of incomplete multivariate data. Chapman; Hall/CRC.

Schmidt, F. L., Oh, I.-S., Le, H., In-Sue, O., \& Le, H. (2006). Increasing the accuracy of corrections for range restriction: implications for selection procedure validities and other 
research results. Personnel Psychology, 59(2), 281-305.

Thorndike, R. L. (1949). Personnel selection; test and measurement techniques. Oxford England: Wiley.

U.S Equal Employment Opportunity Commission. (2020). U.S Equal Employment Opportunity Commission. Retrieved from https://www.eeoc.gov/employers/recordkeeping.cfm 


\section{Appendix}

To estimate the turnover, absenteeism, job performance, etc. under an optimal system, users have two options. For $\mathrm{R}$ aficionados, the selection package in $\mathrm{R}$ provides an easy-touse function called maximizeDV. For those unfamiliar with $\mathrm{R}$, we have developed a shiny app that allows users to estimate the parameters of interest from a web browser.

To use the selection package in R, users must first install it. To install, simply type the code below into the $\mathrm{R}$ console. Note that pound signs (\#) indicate comments.

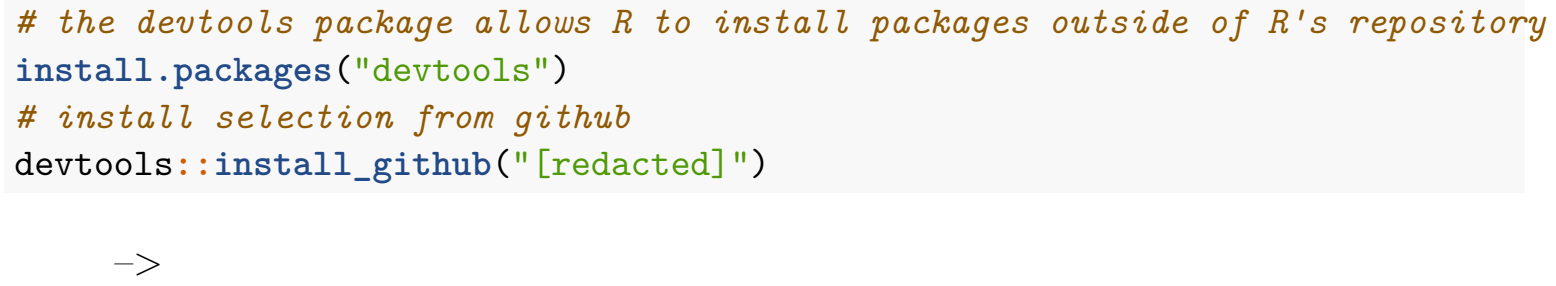

As part of the $R$ package, selection offers various datasets that can be loaded, as in the following code:

\#load the selection package

require (selection)

\# load the selection_data practice dataset

data(selection_data)

Of course, users can also load their own datasets using standard R syntax (e.g., through read.csv or by clicking on File->Import Dataset->... in RStudio).

Once the dataset is loaded, the user can then utilize the maximizeDV function. As with any $\mathrm{R}$ function, the user can type a question mark before the name of the function to access the documentation (in this case, by typing ?maximizeDV). The function takes up to five arguments:

- formula: This is the user-specified equation that specifies how the criterion is associated with the predictors.

- data: This is the name of the dataset loaded in R.

- method: This specifies the functional form of the relationship between the predictor(s) and criterion. It can take one of three arguments: "regression", "logistic", and "poisson". This defaults to "regression".

- imputations: This specifies the number of imputations in the MI model. This defaults to 30 .

- plot: This can take on two values, either TRUE or FALSE. If TRUE, a plot will be returned, otherwise it will not.

The code below shows an illustration, as well as the results generated by R. Here, we are specifying that we wish to predict job performance (JP) from IQ, Biodata, Conscientiousness, and Interview. 


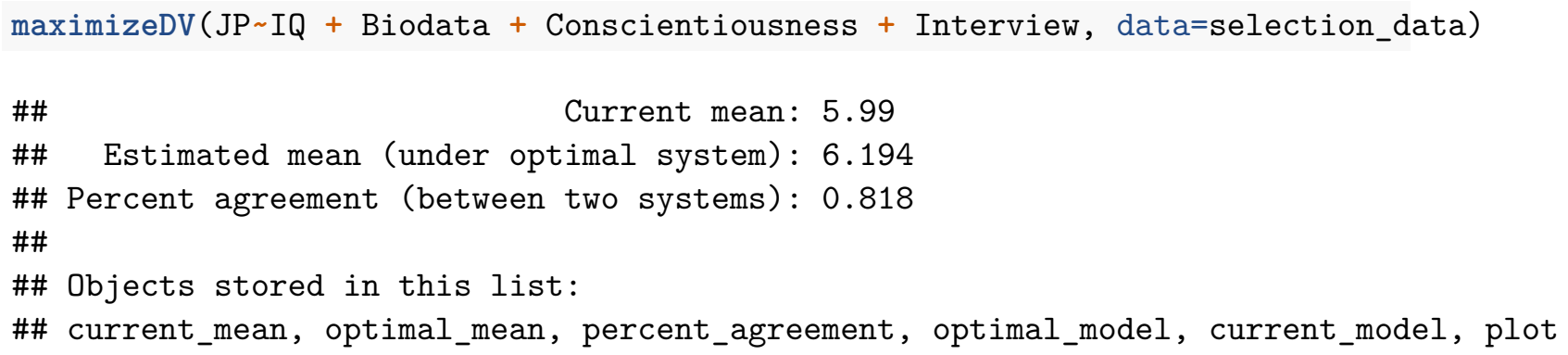

The first statistic shown (labeled "Current mean") reports the current mean of the JP variable (). The second statistic reports the estimated mean under an optimal system ( in this case). The third statistic shows what proportion of applicants on which the two selection systems (current versus optimal) agree. In this case, the optimal and the current system agrees about selecting/rejecting $81.85 \%$ of all applicants.

The following section simply reports the average imputed regression parameters for the model that predicts who is selected under the current system based on the predictors. These estimates are most helpful when a system is not mechanical and may provide insights into showing organizations which variables most strongly influence selection decisions. For our example, we see that Biodata has historically been deemed most important.

fitted_model = maximizeDV(JP IQ + Biodata + Conscientiousness + Interview, data=selection_d fitted_model\$current_model

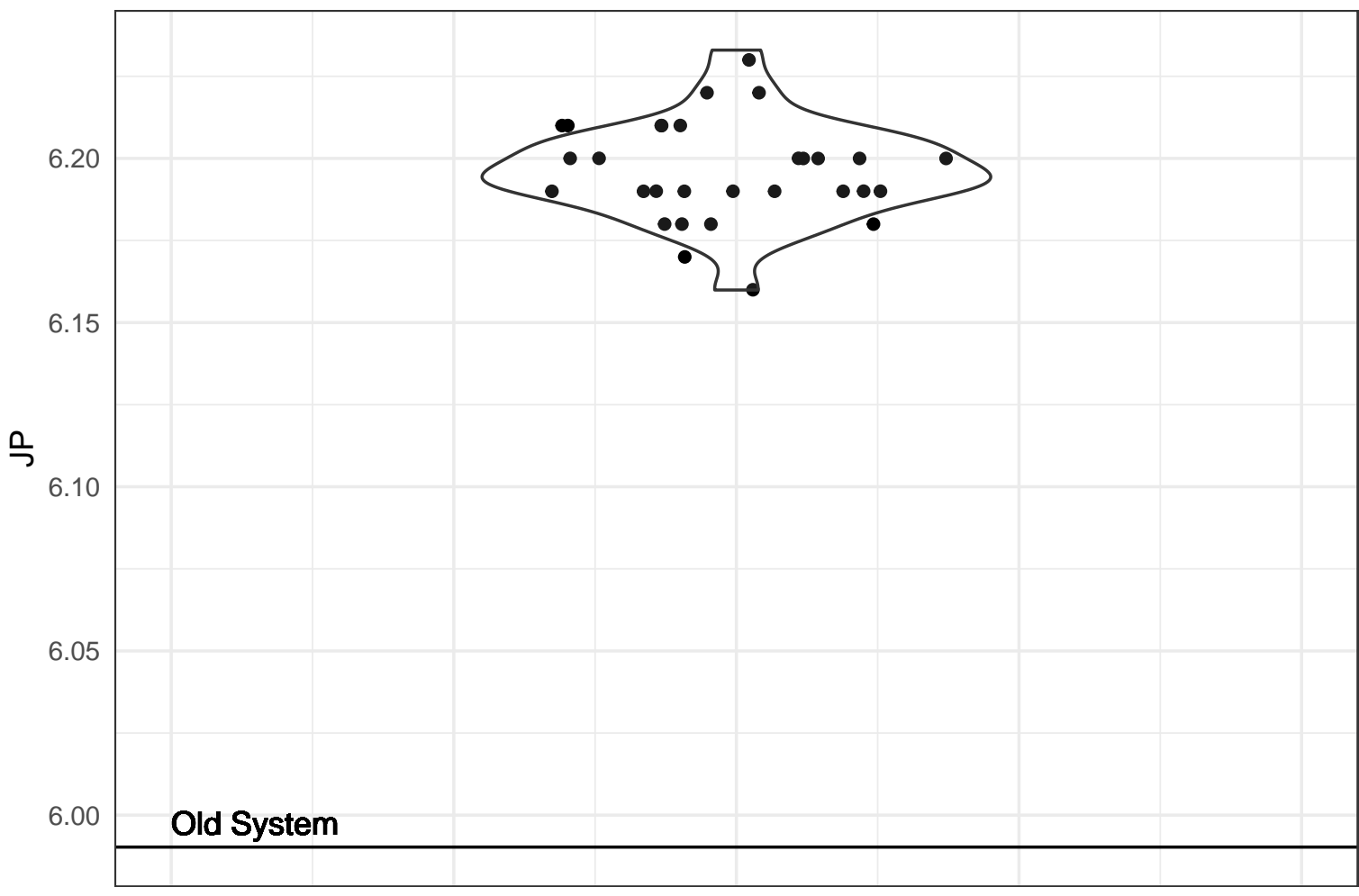

To use the Shiny app, users can visit [redacted]/maximize_criterion. Once there, they 
Table 7

Estimates for the Weights Used to Select Current Applicants Under the Existing Model

\begin{tabular}{lll}
\hline & raw.coefficients & \multicolumn{1}{c}{ OR } \\
\hline (Intercept) & 0.426 & 1.532 \\
IQ & 4.025 & 56.004 \\
Biodata & 8.300 & $4,025.658$ \\
Conscientiousness & -0.418 & 0.658 \\
Interview & 2.075 & 7.961 \\
\hline
\end{tabular}

will see the box shown in Figure 3.

\section{Maximizing the Criterion}

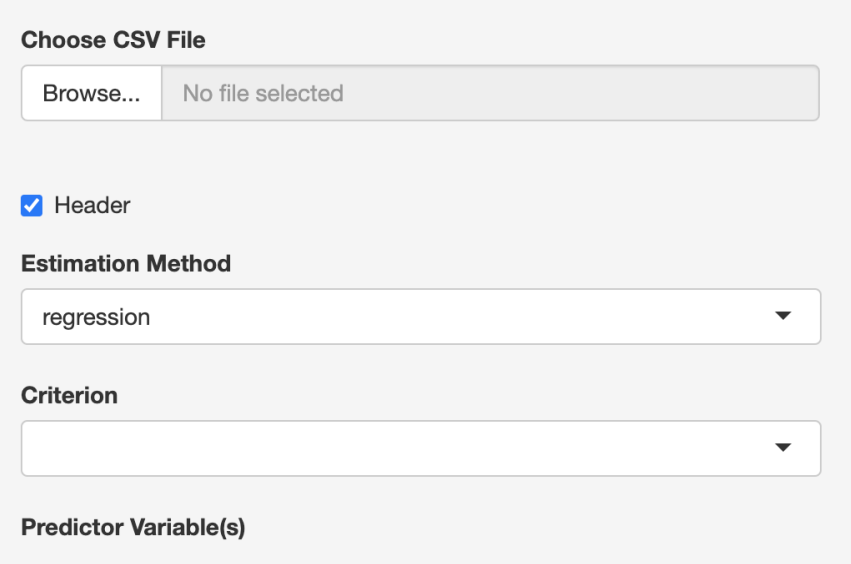

Figure 3. Shiny app dialog box

The user must provide a .csv dataset, then select whether headers (column names) are included in the csv file. Once uploaded, the user selects the estimation method (regression, logistic, or poisson), specifies which variable is the criteria, then selects which variables to include as predictors, as in Figure 4.

\section{References}

Aitken, A. C. (1935). Note on Selection from a Multivariate Normal Population. Proceedings of the Edinburgh Mathematical Society, 4(2), 106-110. doi:10.1017/S0013091500008063

Bobko, P., Roth, P. L., \& Bobko, C. (2001). Correcting the Effect Size of d for Range Restriction and Unreliability. Organizational Research Methods, 4(1), 46-61. Retrieved from https://journals.sagepub.com/doi/pdf/10.1177/109442810141003 

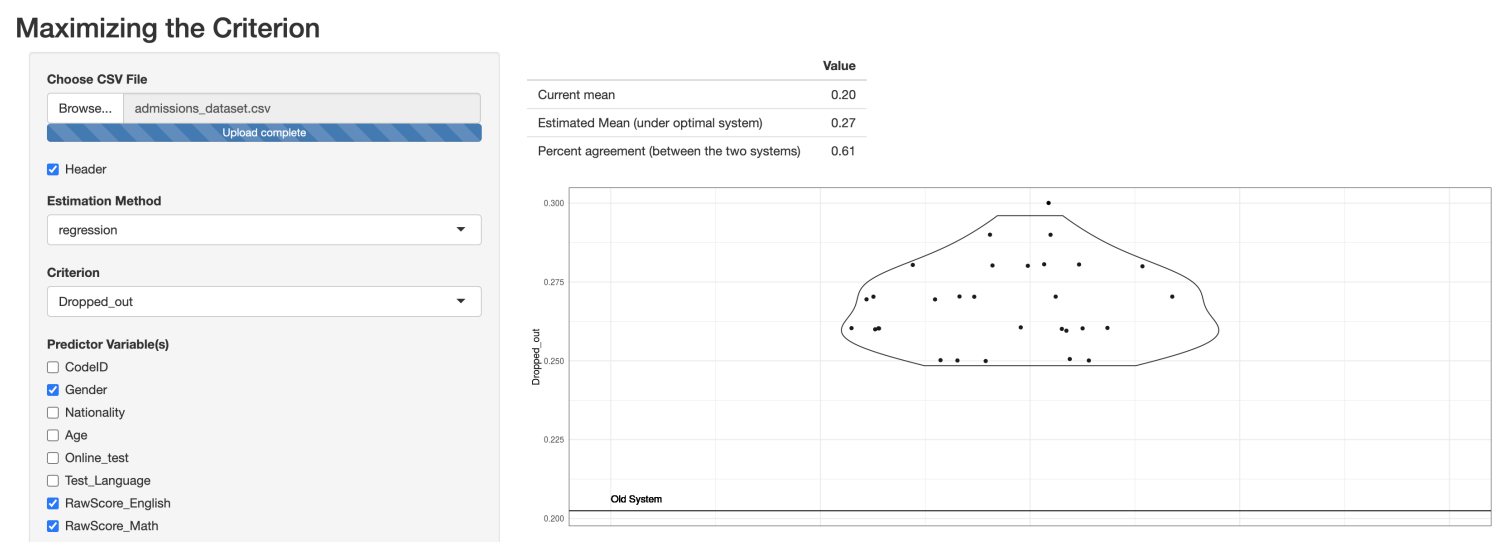

Figure 4. Shiny app example with options selected

Dempster, A. P., Laird, N. M., \& Rubin, D. B. (1977). Maximum likelihood from incomplete data via the EM algorithm. Journal of the Royal Statistical Society: Series B (Methodological), 39(1), 1-22.

Enders, C. K. (2010). Applied missing data analysis. New York, NY: Guilford Press.

Fife, D. A., Hunter, M. D., \& Mendoza, J. L. (2016). Estimating Unattenuated Correlations With Limited Information About Selection Variables: Alternatives to Case IV. Organizational Research Methods, 19(4). doi:10.1177/1094428115625323

Fife, D. A., Mendoza, J. L., \& Berry, C. M. (2017a). Estimating Incremental Validity Under Missing Data. Multivariate Behavioral Research, 52(2). doi:10.1080/00273171.2016.1259099

Fife, D. A., Mendoza, J. L., \& Berry, C. M. (2017b). Estimating Incremental Validity Under Missing Data. Multivariate Behavioral Research, 52(2), 164-177.

Fife, D. A., Mendoza, J. L., \& Terry, R. (2012). The Assessment of Reliability Under Range Restriction. Educational and Psychological Measurement, 72(5), 862-888. doi:10.1177/0013164411430225

Ghiselli, E. E., Campbell, J. P., \& Zedeck, S. (1981). Measurement Theory for the Behavioral Sciences.

Gross, A. L., \& McGanney, M. L. (1987). The restriction of range problem and nonignorable selection processes. Journal of Applied Psychology, 72(4), 604-610.

Heckman, J. J. (1979). Sample Selection Bias as a Specification Error. Econometrica, $47(1), 153-161$. doi:10.2307/1912352

Hunter, J. E., \& Schmidt, F. L. (2004). Methods of meta-analysis: correcting error and bias in research findings. Thousand Oaks, CA: Sage.

Kuncel, N. R., Klieger, D. M., Connelly, B. S., \& Ones, D. S. (2013). Mechanical versus clinical data combination in selection and admissions decisions: A metaanalysis. Journal of Applied Psychology, 98(6), 1060-1072. doi:10.1037/a0034156 
Lawley, D. N. (1944). A Note on Karl Pearson's Selection Formulae. Proceedings of the Royal Society of Edinburgh. Section A. Mathematical and Physical Sciences, 62(01), 28-30. doi:https://doi.org/10.1017/S0080454100006385

Le, H., Oh, I., Schmidt, F. L., \& Wooldridge, C. D. (2016). Correction for range restriction in meta-analysis revisited: Improvements and implications for organizational research. Personnel Psychology, 69(4), 975-1008.

Li, J. C.-H. (2015). Cohen's d Corrected for Case IV Range Restriction: A More Accurate Procedure for Evaluating Subgroup Differences in Organizational Research. Personnel Psychology, 68(4), 899-927. doi:10.1111/peps.12096

Little, R. J. A., \& Rubin, D. B. (2014). Statistical analysis with missing data. Hoboken, NJ: John Wiley \& Sons.

Lord, F. I., \& Novick, M. R. (1968). Statistical theories of mental test scores. Cambridge, MA: Addison-Wesley.

Meehl, P. (1954). Clinical versus statistical prediction: A theoretical analysis and a review of theevidence. Minneapolis, MN: University of Minnesota.

Mendoza, J. L. (1993). Fisher Transformations for Correlations Corrected for Selection and Missing Data. Psychometrika, 58(4), 601-615.

Pearson, K. (1903). Mathematical Contributions to the Theory of Evolution. XI. On the Influence of Natural Selection on the Variability and Correlation of Organs. Philosophical Transactions of the Royal Society of London. Series A, Containing Papers of a Mathematical or Physical Character, 200, 1-66.

Pfaffel, A., Kollmayer, M., Schober, B., \& Spiel, C. (2016). A missing data approach to Correct for direct and indirect range restrictions with a dichotomous criterion: A simulation study. PLoS ONE, 11(3), e0152330. doi:10.1371/journal.pone.0152330

Roth, P. L. (1994). Missing data: a conceptual review for applied psychologists. Personnel Psychology, 47(3), 537-560. doi:10.1111/j.1744-6570.1994.tb01736.x

Rubin, D. B. (1976). Inference and missing data. Biometrika, 63(3), 581-592. doi:10.1093/biomet/63.3.581

Rubin, D. B. (1987). Multiple imputation for nonresponse in surveys. New York, NY: Wiley.

Sackett, P. R., Laczo, R. M., \& Arvey, R. D. (2002). The effects of range restriction on estimates of criterion interrater reliability: Implications for validation research. Personnel Psychology, 55(4), 807-825.

Sackett, P. R., \& Yang, H. (2000). Correction for range restriction: An expanded typology. Journal of Applied Psychology, 85(1), 112-118.

Schafer, J. L. (1997). Analysis of incomplete multivariate data. Chapman; Hall/CRC. 
Schmidt, F. L., Oh, I.-S., Le, H., In-Sue, O., \& Le, H. (2006). Increasing the accuracy of corrections for range restriction: implications for selection procedure validities and other research results. Personnel Psychology, 59(2), 281-305.

Thorndike, R. L. (1949). Personnel selection; test and measurement techniques. Oxford England: Wiley.

U.S Equal Employment Opportunity Commission. (2020). U.S Equal Employment Opportunity Commission. Retrieved from https://www.eeoc.gov/employers/ recordkeeping.cfm

Aitken, A. C. (1935). Note on Selection from a Multivariate Normal Population. Proceedings of the Edinburgh Mathematical Society, 4(2), 106-110. doi:10.1017/S0013091500008063

Bobko, P., Roth, P. L., \& Bobko, C. (2001). Correcting the Effect Size of d for Range Restriction and Unreliability. Organizational Research Methods, 4(1), 46-61. Retrieved from https://journals.sagepub.com/doi/pdf/10.1177/109442810141003

Dempster, A. P., Laird, N. M., \& Rubin, D. B. (1977). Maximum likelihood from incomplete data via the EM algorithm. Journal of the Royal Statistical Society: Series B (Methodological), 39(1), 1-22.

Enders, C. K. (2010). Applied missing data analysis. New York, NY: Guilford Press.

Fife, D. A., Hunter, M. D., \& Mendoza, J. L. (2016). Estimating Unattenuated Correlations With Limited Information About Selection Variables: Alternatives to Case IV. Organizational Research Methods, 19(4). doi:10.1177/1094428115625323

Fife, D. A., Mendoza, J. L., \& Berry, C. M. (2017a). Estimating Incremental Validity Under Missing Data. Multivariate Behavioral Research, 52(2). doi:10.1080/00273171.2016.1259099

Fife, D. A., Mendoza, J. L., \& Berry, C. M. (2017b). Estimating Incremental Validity Under Missing Data. Multivariate Behavioral Research, 52(2), 164-177.

Fife, D. A., Mendoza, J. L., \& Terry, R. (2012). The Assessment of Reliability Under Range Restriction. Educational and Psychological Measurement, 72(5), 862-888. doi:10.1177/0013164411430225

Ghiselli, E. E., Campbell, J. P., \& Zedeck, S. (1981). Measurement Theory for the Behavioral Sciences.

Gross, A. L., \& McGanney, M. L. (1987). The restriction of range problem and nonignorable selection processes. Journal of Applied Psychology, 72 (4), 604-610.

Heckman, J. J. (1979). Sample Selection Bias as a Specification Error. Econometrica, 47(1), 153-161. doi:10.2307/1912352

Hunter, J. E., \& Schmidt, F. L. (2004). Methods of meta-analysis: correcting error and bias in research findings. Thousand Oaks, CA: Sage. 
Kuncel, N. R., Klieger, D. M., Connelly, B. S., \& Ones, D. S. (2013). Mechanical versus clinical data combination in selection and admissions decisions: A metaanalysis. Journal of Applied Psychology, 98(6), 1060-1072. doi:10.1037/a0034156

Lawley, D. N. (1944). A Note on Karl Pearson's Selection Formulae. Proceedings of the Royal Society of Edinburgh. Section A. Mathematical and Physical Sciences, 62(01), 28-30. doi:https://doi.org/10.1017/S0080454100006385

Le, H., Oh, I., Schmidt, F. L., \& Wooldridge, C. D. (2016). Correction for range restriction in meta-analysis revisited: Improvements and implications for organizational research. Personnel Psychology, 69(4), 975-1008.

Li, J. C.-H. (2015). Cohen's d Corrected for Case IV Range Restriction: A More Accurate Procedure for Evaluating Subgroup Differences in Organizational Research. Personnel Psychology, 68(4), 899-927. doi:10.1111/peps.12096

Little, R. J. A., \& Rubin, D. B. (2014). Statistical analysis with missing data. Hoboken, NJ: John Wiley \& Sons.

Lord, F. I., \& Novick, M. R. (1968). Statistical theories of mental test scores. Cambridge, MA: Addison-Wesley.

Meehl, P. (1954). Clinical versus statistical prediction: A theoretical analysis and a review of theevidence. Minneapolis, MN: University of Minnesota.

Mendoza, J. L. (1993). Fisher Transformations for Correlations Corrected for Selection and Missing Data. Psychometrika, 58(4), 601-615.

Pearson, K. (1903). Mathematical Contributions to the Theory of Evolution. XI. On the Influence of Natural Selection on the Variability and Correlation of Organs. Philosophical Transactions of the Royal Society of London. Series A, Containing Papers of a Mathematical or Physical Character, 200, 1-66.

Pfaffel, A., Kollmayer, M., Schober, B., \& Spiel, C. (2016). A missing data approach to Correct for direct and indirect range restrictions with a dichotomous criterion: A simulation study. PLoS ONE, 11(3), e0152330. doi:10.1371/journal.pone.0152330

Roth, P. L. (1994). Missing data: a conceptual review for applied psychologists. Personnel Psychology, 47(3), 537-560. doi:10.1111/j.1744-6570.1994.tb01736.x

Rubin, D. B. (1976). Inference and missing data. Biometrika, 63(3), 581-592. doi:10.1093/biomet/63.3.581

Rubin, D. B. (1987). Multiple imputation for nonresponse in surveys. New York, NY: Wiley.

Sackett, P. R., Laczo, R. M., \& Arvey, R. D. (2002). The effects of range restriction on estimates of criterion interrater reliability: Implications for validation research. Personnel Psychology, 55(4), 807-825. 
Sackett, P. R., \& Yang, H. (2000). Correction for range restriction: An expanded typology. Journal of Applied Psychology, 85(1), 112-118.

Schafer, J. L. (1997). Analysis of incomplete multivariate data. Chapman; Hall/CRC.

Schmidt, F. L., Oh, I.-S., Le, H., In-Sue, O., \& Le, H. (2006). Increasing the accuracy of corrections for range restriction: implications for selection procedure validities and other research results. Personnel Psychology, 59(2), 281-305.

Thorndike, R. L. (1949). Personnel selection; test and measurement techniques. Oxford England: Wiley.

U.S Equal Employment Opportunity Commission. (2020). U.S Equal Employment Opportunity Commission. Retrieved from https://www.eeoc.gov/employers/ recordkeeping.cfm 